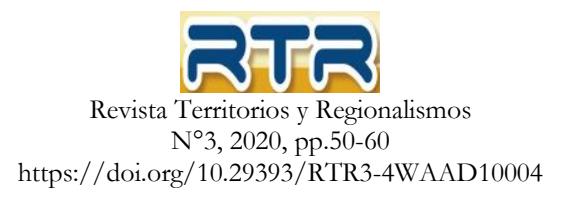

\title{
Avances y déficits del proceso descentralizador con foco regional en Chile
}

Progress and deficits in the decentralization process with a regional focus in Chile

Walter Bruno Azevedo Gomes*

\begin{abstract}
Resumen: Chile se encuentra hoy inmerso en un proceso de descentralización del Estado sin precedentes, ya que históricamente su contexto político se ha caracterizado por una cultura predominantemente centralista. En el ámbito de descentralización política, el país exhibe un déficit en comparativo a las democracias modernas, donde las máximas autoridades ejecutivas de los gobiernos subnacionales son designadas por el gobierno central. La futura elección democrática de gobernadores regionales de 2021 corresponde un cambio importante en toda esa dinámica establecida.

Este trabajo está orientado a estudiar la descentralización política, revisando el desarrollo que han tenido con las reformas en Chile desde el 2014, tomando como referencia la relatoría final de la Comisión Asesora Presidencial para la Descentralización y el Desarrollo Regional, que fue compuesta por un grupo plural y una metodología participativa que permitió la sistematización de las propuestas y las directrices en post de la descentralización en el país. Así, en la discusión y conclusión de la investigación se realiza un análisis descriptivo, mediante un balance de documentos oficiales, encuestas, artículos y libros, de los avances y desafíos actuáis de la descentralización política chilena.
\end{abstract}

Palabras-clave: descentralización; gobernadores regionales; desarrollo territorial; Chile

\begin{abstract}
Chile is currently immersed in an unprecedented process of decentralization of the State, since historically its political context has been characterized by a predominantly centralist culture. In the field of political decentralization, the country exhibits a deficit compared to modern democracies, where the highest executive authorities of subnational governments are appointed by the central government. The future democratic election of regional governors in 2021 corresponds to an important change in all this established dynamic.

This work is aimed at studying political decentralization, reviewing the development that the reforms have had in Chile since 2014, taking as a reference the final report of the Presidential Advisory Commission for Decentralization and Regional Development, which was composed of a group plural and a participatory methodology that allowed the systematization of the proposals and the guidelines in post of decentralization in the country and from that, review the impact of the reforms on the progress of the regions. Thus, in the discussion and conclusion of the research, a descriptive analysis is carried out, through a balance of official documents, surveys, articles and books, of the progress and current challenges of Chilean political decentralization.
\end{abstract}

\footnotetext{
* Brasileño, Psicólogo, Becario de La Agencia de Cooperación Internacional de Chile para el Desarrollo (AGCID), Magister en política y Gobierno en la Universidad de Concepción. Correo electrónico walterbrunoazevedo@gmail.com/ https://orcid.org/0000-0002-9024-5030
} 


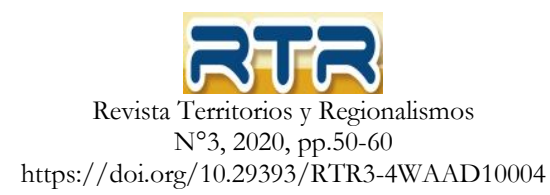

Keywords: decentralization; regional governors; territorial development; Chile

Recibido: 17 junio 2020 Aceptado: 22 septiembre 2020

\section{Introducción}

Chile es el único país de Sudamérica en el cual las autoridades regionales no son designadas directamente por votación democrática, convirtiéndolo en uno de los países más centralizados de la región en términos políticos administrativos. Al contrario de lo que sucede en sus países vecinos, donde sus autoridades regionales son electas por votación directa, tanto en los países federales como Argentina, Brasil y Venezuela, como también en los países unitarios como Bolivia, Colombia, Ecuador, Paraguay, Perú y Uruguay (Cossani \& Bonivento, 2014).

La centralización del Estado, de gran importancia en el siglo pasado, hoy no es eficaz para garantizar el desarrollo social. Según Von Baer (2016) Chile posee los peores ingresos y gastos públicos asignados a los niveles municipalidades y regionales, lo que impacta directamente en el progreso territorial, generando desigualdad acentuada en sus regiones.

Chile se encuentra inmerso en un proceso de descentralización histórico. Demandas como la reivindicación de una nueva constitución del país y descentralización del Estado, presentes desde la creación de la República y acentuadas durante las recientes manifestaciones populares, evidencian que Chile está en camino de un nuevo ciclo político. (Cartes, 2018)

La elaboración del presente trabajo se centra en la variante política de la descentralización y tiene por objetivo analizar su impacto en el desarrollo territorial chileno a partir del año 2014, con las propuestas elaboradas por la Comisión asesora presidencial para la descentralización y el desarrollo regional y su avance hasta el año de 2020.

\section{Marco teórico}

\section{Desarrollo territorial y Descentralización}

La Organización para la Cooperación y el Desarrollo Económico (OCDE), en su estudio realizado en 2009, afirma que, a pesar de los considerables avances económicos nacionales de las últimas décadas, principalmente comparado a los países vecinos, este crecimiento no ha sido acompañado por el desarrollo de las regiones chilenas, las cuales en su mayoría registran bajas tasas de crecimiento. Uno de los factores apuntados es que la economía chilena depende de algunos sectores ubicados en regiones especificas del país donde se concentra la inversión pública y privada.

La minería (23\% del PIB en 2006) y los servicios financieros (14\% del PIB) están ubicados principalmente en Antofagasta y la región metropolitana, respectivamente. Antofagasta genera casi $50 \%$ del PIB del sector minero, si se incluye a Tarapacá y Atacama, las otras dos regiones nortinas de producción minera, esa tasa aumenta a 75\%. Asimismo, la región metropolitana es responsable de casi un 77\% de PIB de los servicios financieros (OCDE,2009 p.48). 


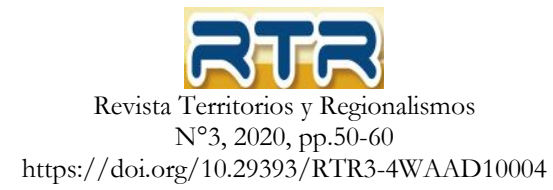

Esa concentración económica que estructura el país genera un gran impacto en la desigualdad regional. Revelando altos niveles de pobreza y bajo crecimiento en las regiones cuya economía se basa mayormente en la actividad agrícola, como Araucanía, Maule y Coquimbo.

Cuando abordamos el desarrollo territorial, es intrínseca su relación con la calidad de vidas de las personas que habitan en esas regiones. Para Marcel (2016) gran parte de la actividad económica se desarrolla en espacios geográficos específicos, dentro de un mismo país. Por lo anterior, es necesario reconocer al territorio como el espacio concreto, donde ocurren los procesos económicos que determinan la capacidad para producir y competir entre las regiones. El autor defiende que los territorios tengan oportunidad de desarrollar sus ventajas comparativas, con uso estratégico de las dinámicas disponibles, así "una buena política territorial que apunte al pleno aprovechamiento de las economías de la aglomeración y que potencie la competitividad de las regiones debería ser parte de un esfuerzo por elevar la productividad y el potencial de crecimiento del conjunto del país" (p.177)

En el ámbito latinoamericano el concepto de descentralización es entendido como "un proceso de reforma del Estado compuesto por un conjunto de políticas públicas que transfieren responsabilidades, recursos o autoridad de los niveles más altos de gobierno a los más bajos" (Montecinos, 2020 p. 03 apud Falleti, 2006).

En el contexto chileno, el concepto de descentralización está ligado a tres dimensiones analíticas fundamentales: administrativa, fiscal y política. En términos generales, la descentralización administrativa prevé la distribución de competencias entre el gobierno nacional, regional y municipal. La descentralización fiscal, por su parte, consiste en el gerenciamiento de decisión de ingreso y gasto público y, por último, la descentralización política discute la participación ciudadana y su representatividad, enfatizando la distribución del poder político tanto de las autoridades electas como a los ciudadanos en el proceso de toma de decisiones públicas. (Dazarola, 2019)

Para Marcel (2016) la descentralización política se refiere al grado de autonomía de las autoridades locales, sus competencias y sus mecanismos de designación. Es por esta razón que se hace necesaria la existencia de normativas que garanticen la autonomía de autoridades locales y regionales. En sus palabras, "la intensidad de la descentralización política depende del ámbito de las facultades que los gobiernos subnacionales pueden ejercer con autonomía, incluyendo el fiscal, de los recursos de que disponen y de la necesidad de coordinación con órganos desconcentrados del gobierno central” (p.173). Orellana \& Arenas (2019) en aquiescencia a lo expuesto, apuntan que uno de los retos políticos actuales es la necesidad de que se reconozca progresivamente la autonomía regional a través de un acto político amplio y convergente, que equilibre el desarrollo y calidad de vida entre y al interior de las regiones del país.

A pesar de que la finalidad de este trabajo es analizar la descentralización política, es importante enfatizar que, en la praxis, esta es acompañada por el avance simultáneo y convergente de los procesos de descentralización administrativa y fiscal (Von Baer, Rozas \& Bravo, 2016). En el caso chileno, la descentralización política pasa por un conjunto de reformas electorales y constitucionales, es por esto que, para su estudio, conviene considerar no solo los aspectos teóricos, sino también el aspecto legal del concepto de descentralización (Opazo, 2020). En resumen, se pretende postular la descentralización como una política nacional que, promueva la autonomía, desarrollo y diversidad de las regiones.

\section{Antecedentes históricos y reformas políticas}

Para el avance de la discusión, es necesario entender el contexto sociopolítico y la tensión existente entre el centralismo y la descentralización del Estado. Sin embargo, no se pretende agotar el tema, por el 


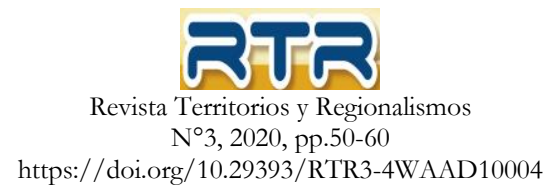

contrario, el objetivo aquí es exponer los principales hitos y reformas políticas que son relevantes para el análisis propuesto.

Dazarola (2019) señala que, a partir de la década de los 90 se ha vivenciado un movimiento a favor de la reestructuración de la administración a nivel regional, muestra de ello es la promulgación de la Ley $\mathrm{N}^{\circ} 19.175$, la cual tiene como consecuencia la creación de los gobiernos y administración regional (LOCGAR).

Por otra parte, en el año 2009 se promulga la ley $\mathrm{N}^{\circ} 20.390$, la cual introduce una serie de reformas a la Constitución Política en materia de gobierno y descentralización. Estos cambios legislativos, fueron un hecho fundamental para avanzar en el proceso y la discusión de la descentralización regional. (Opazo, 2020)

En este escenario, podemos identificar algunos actores que habían promovido el movimiento mencionado anteriormente como Organizaciones de la Sociedad Civil, como CORBIOBIO (Región de Biobío), CORCHILE, CONAREDE, y grupos recientemente más activo como la SINERGIA, AUR (Grupo de Universidades Regionales), Fundación Piensa (Región de Valparaíso), organismos internacionales como la OCDE, citado anteriormente y la Fundación Chile Descentraliza, que es una organización plural de la sociedad civil, que promueve propuestas de descentralización en el país. Cabe destacar que las encuestas de opinión realizadas en el año de 2013 apuntaban que el 73\% de los chilenos y chilenas están a favor de la descentralización (Opazo 2020)

En ese mismo año, seis años de después de la tramitación de la ley 20.390, concretase su promulgación mediante la ley 20.678, permitiendo la elección directa y universal de los consejeros regionales, que señala un aumento la participación ciudadana en el proceso de elección. Opazo (2020) denominó a ese conjunto de reformas, como 'leyes de descentralización ${ }^{1}$ ', donde Chile pasa de un modelo de regionalización desconcentrada a un modelo de descentralización territorial, provocando un cambio entre las relaciones intergubernamentales en diferentes niveles.

En los años del primer gobierno de Sebastián Piñera (2010-2014) no resultó en grandes avances en términos de descentralización. Pero Valenzuela (2015) destaca dos momentos durante este gobierno, la primera es la elección directa de los consejeros regionales en 2013, que fue formulada durante el primero mandato de la presidenta Bachelet (2006-2009) e implementado durante el Gobierno de Piñera y el segundo fue la creación de un proyecto de fortalecimiento de los gobiernos regionales y de traspaso de competencias, pero sin plazos perentorios ni servicios explícitos. Von Baer y Portales (2019) narran que, mismo con lo que representaba la primera elección directa de consejeros regionales, hubo un alto nivel de votos nulos y blancos $(12,7 \%)$ y justifica que se debe en parte por la ausencia de una campaña previa de información y motivación ciudadana.

En el año de 2015, Iriarte (2016) realizó una encuesta a nivel nacional aplicada a 80 consejeros y consejeras regionales (CORE). Como resultado, el estudio presenta el análisis de la percepción de los CORE sobre el proceso de descentralización y democratización de la elección para consejeros, destacando algunas conclusiones de ese estudio, que ilustran la percepción del poco avance y optimismo en relación con el futuro.

- $\quad 59 \%$, piensa que la democratización en su elección no ha cambiado nada o solo un poco la función que realizan actualmente;

\footnotetext{
${ }_{1}^{1}$ Opazo (2020) Aborda leyes de descentralización, como un conjunto de leyes aprobados a partir de 2009, además del recorte expuesto, como la Reforma Constitucional Ley 20.990/2017 que permite la elección del gobernador regional; la ley 21.073/2018 que regula la elección del gobernador regional y la ley 21.074 que regula la transferencia de competencias del gobierno central a los gobiernos regionales.
} 


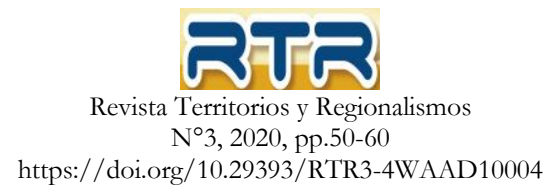

- 96\% de los entrevistados consideró nulo o insignificante los avances descentralizadores propuesto hasta el momento, contra el $4 \%$ que declaro significativo el progreso de la descentralización;

- Con relación al futuro del país la mayoría de los encuestados, $67 \%$, cree en la perspectiva de un Chile descentralizado hasta el 2030.

En el programa de gobierno de Michelle Bachelet, en 2014, se crea una Comisión asesora presidencial para la descentralización y el desarrollo regional, generando en el país un conjunto de propuestas para una política integral de descentralización. Esa comisión se caracteriza por un "conjunto de propuestas para descentralizar Chile, con el propósito fundamental de romper las inequidades territoriales, transferir poder y generar mejor democracia en las comunas y regiones, y poner a Chile en la senda de un desarrollo integral, impensable sin sus territorios" (Comisión Asesora Presidencial, 2014 p.09), Ortiz \& Valenzuela (2018) destacan de la relatoría final tres medidas fundamentales: elección de intendentes, traspaso de competencias y ley de rentas regionales. En suma, en el plan de descentralización, presupone autonomía política, administrativa y fiscal, donde Chile pasa de un Estado unitario a un Estado descentralizado. (Comisión Asesora Presidencial, 2014)

Así, Montecinos (2020) fragmenta la descentralización regional en Chile en tres periodos, los cuales se presentan de manera resumida a continuación:

I. $1974-1990$, cuando se instala el actual modelo de desconcentración político-administrativa regional (primeras oficinas ministeriales y servicios públicos en regiones), a este proceso se le denomina "Regionalización".

II. 1990 - 2013, en este periodo se consolida un modelo con predominancia de la desconcentración basada en la organización diseñada en 1974. Esta estructura se complementa con la creación del gobierno regional, por la ley 19.175 en 1992, compuesto por el consejo regional y su ejecutivo (intendente regional), cuya principal función es asignar recursos (FNDR) en función de la demanda promovida por los municipios y servicios públicos.

III. 2013 - 2021, esta etapa comienza con las elecciones por votación directa de los consejeros regionales, ley $\mathrm{N}^{\circ} 20.678$, y se extiende hasta la futura de elección democrática de los gobernadores regionales.

Opazo (2020) por otra parte, descompone el proceso de descentralización del país en dos etapas:

I. 2018 - 2024, caracterizado por la transición o instalación del nuevo modelo de gobierno regional. Pasando de un modelo de regionalización desconcentrada a un modelo de descentralización territorial. La creación de leyes de descentralización y las futuras elección directa del gobernador y el consejo regional,

II. Posterior a 2024 - Denominado por el autor como como un modelo Estado flexible, donde entran en vigor todas las leyes y reglamentos. Donde puedes medir el efecto de la transferencia de competencia desde ministerios y servicios públicos a los gobiernos 


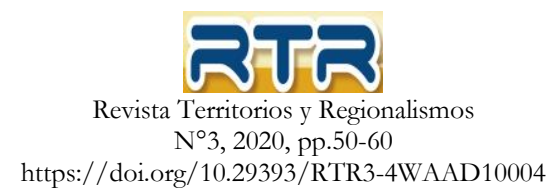

regionales y su capacidad de reversar la transferencia y los cambios en las estructuras del gobierno central y regional.

Como se ha visto, Chile históricamente ha sido conocido como un país centralizado. Ortiz \& Valenzuela (2018) sostienen la existencia de factores culturales presentes en el país, como la tradición centralista de la élite chilena, donde existe un predominio de una cultura que no acepta distribuir poder. Eso, sumado a la resistencia frente a procesos descentralizadores, resulta en un impacto negativo en el progreso de las regiones y consecuentemente en el crecimiento del país.

\section{Discusión}

\section{Análisis de los Avances y Déficits en el proceso de Descentralización de 2014-2020}

La Comisión asesora presidencial para la descentralización y el desarrollo regional, es enfática al tratar la descentralización y su relación con el desarrollo de las regiones chilenas, y declara que "si se quiere alcanzar un desarrollo económico y social equilibrado y sustentable, reactivar la economía potenciando los territorios, modernizar el Estado y profundizar nuestra democracia, debemos impulsar como política de Estado un conjunto de transformaciones dirigidas a una efectiva descentralización y desarrollo local-regional" (Comisión Asesora Presidencial, 2014, p.10). Esa comisión específica un marco en la discusión sobre la descentralización en el país, reconociendo que una de las medidas esenciales para el avance de todo el proceso es la elección popular del ejecutivo de los gobiernos regionales y la principal medida para hacer efectiva la descentralización política, entendiendo que "extender la democracia regional a la elección de todas sus autoridades dinamiza el proceso descentralizador y lo hace concreto, creíble e irreversible" (Comisión Asesora Presidencial, 2014 p. 27).

Para seguir ese camino haría necesaria una reforma constitucional que permita esa nueva organización de los gobiernos regionales, debido a que la constitución del país limitaba la competencia de los gobiernos regionales.

En su informe final, argumentaba la necesidad de "una definición constitucional precisa de las competencias de los gobiernos regionales no sólo ayuda a reducir los eventuales y previsibles conflictos de competencias que puedan suscitarse entre los distintos niveles de gobierno, sino que es, además, condición necesaria para atribuir al Tribunal Constitucional la función esencial de dirimir tales controversias" (Comisión Asesora Presidencial, 2014, p.28)

Sobre el informe final de la comisión, Portales (2016) en su estudio subraya que:

La Comisión Asesora Presidencial en Descentralización y Desarrollo Regional cumplió oportunamente con el encargo y formuló un conjunto de recomendaciones que se conciben como una "política de Estado" con el concepto de "Estado Unitario Descentralizado". Los elementos constitutivos de esa política recogen todas y cada una de las propuestas programáticas y les da un ordenamiento coherente en torno a cinco ejes: descentralización política, descentralización administrativa, descentralización fiscal, desarrollo de capital humano calificado y participación y control social del proceso. (Portales, 2016 p.89)

En el año de 2015, son enviados los proyectos al senado con el objetivo de regular las elecciones directas de los gobernadores regionales. En al año siguiente es cuando la Comisión de Gobierno, 


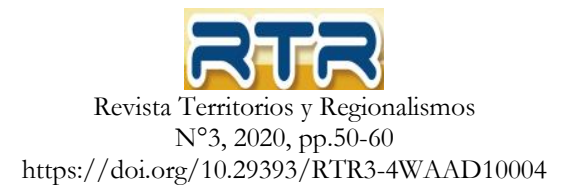

Descentralización y Regionalización del Senado elabora su informe con lo que el proyecto finaliza para su votación general en el Senado, que se concretiza en marzo de 2016 (Von Baer, Rozas \& Bravo, 2016). Conforme a lo expuesto por esos autores había una lentitud legislativa y una falta de urgencias fijadas por el poder ejecutivo en concretizar para el mismo año las elecciones de gobernadores, como había sugerido la Comisión Presidencial.

En el año de 2017, con la aprobación de la Reforma Constitucional de ley $20.990^{2}$, el proceso de descentralización prospera, generando una reforma constitucional para la elección popular y finalmente, en 2018 con las leyes $\mathrm{N}^{\circ} 21.073$ donde se encuentra regulada la elección de gobernadores regionales y la ley $\mathrm{N}^{\circ} 21.074$ que introduce una serie de modificaciones a distintos cuerpos legales con el objetivo de fortalecer la regionalización en Chile, adjudicando mayor autonomía en su gestión y aumento de funciones y atribuciones de los gobiernos regionales, la cual constituye un avance sustantivo en materia de descentralización política para Chile.

El Índice de Desarrollo Regional - IDERE-, es una herramienta que mide el desarrollo a nivel territorial de cada una de las regiones del país, desde una perspectiva multidimensional (salud, educación, bienestar socioeconómico, actividad económica, conectividad, seguridad y medio ambiente), donde los índices son mensurados entre 0 y 1 ( 0 expresa el desarrollo mínimo y 1 el máximo). Este estudio revela que durante el período 2017-2019 (las dos últimas investigaciones) la tendencia de todas las regiones ha sido la mejora de sus indicadores general, aunque existen diferencias en la velocidad con las que estas mejoras se han desarrollado entre las regiones. (IDERE, 2019). Sin embargo, esto se condice con la tendencia de un crecimiento regional percibida en los últimos diez años, como se muestra en la tabla ${ }^{3}$ a continuación

\section{Evolución del IDERE 2010-2019}

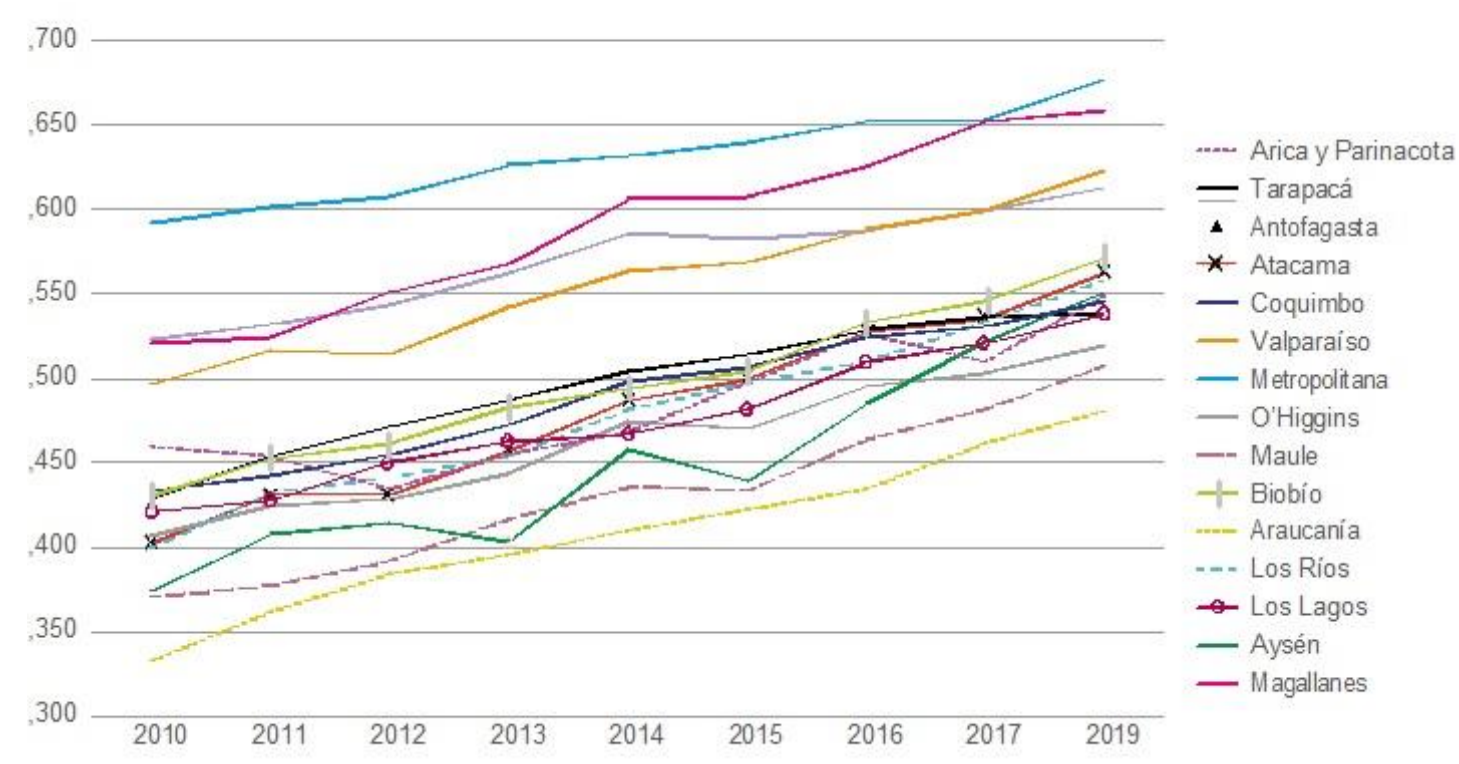

\footnotetext{
${ }^{2}$ La Ley 20.990 originalmente previa la elección para octubre del año 2020, pero debido la Pandemia fue postergada para abril de 2021.

3 elaboración IDERE (2019), sin la dimensión Sustentabilidad y medioambiente que solo ha estado disponible desde la versión 2017 en adelante.
} 


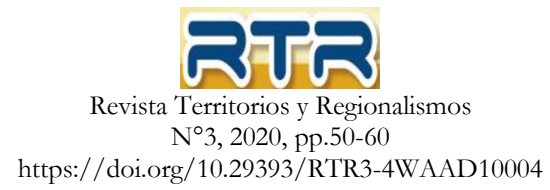

Los resultados indican un mayor desarrollo en la región de Magallanes, es la que actualmente lidera el ranking. Seguido por las regiones Metropolitana, Valparaíso, y Antofagasta, respectivamente. En contrapartida, Araucanía se mantiene como la región con menor desarrollo del país. Junto a ella, en el grupo de desarrollo bajo, se encuentran las regiones de O'Higgins y Maule. (IDERE, 2019).

Estos resultados se corroboran con los presentados por la OCDE (2009), ya que, las regiones que más se desarrollaron, son las que muestran el mayor PIB per cápita confirmando que poco ha cambiado de 2009 hasta 2019.

Las regiones orientadas hacia la minería y la capital (Región Metropolitana de Santiago, o RM) muestran el mayor PIB per cápita de las regiones chilenas. Los mayores niveles de ingreso per cápita se registran en las regiones nortinas de Antofagasta (USD 20.411 a PPP 2004) y Tarapacá (USD 10.443), que tienen una intensa actividad minera, junto con la escasamente poblada región sureña de Magallanes (USD 11.543) y la región Metropolitana (USD 10.111). Sus niveles de PIB per cápita son hasta cinco veces más alto que en las regiones de la Araucanía (USD 3.951) y Coquimbo (USD 4.887) (OCDE, 2009 p. 50).

El Barómetro Regional (2019) estudia la percepción ciudadana acerca de las regiones del país, en su última encuesta verifico $40 \%$ de las personas, en nivel nacional, confirme que las elecciones directas de los gobernadores será un impulso para el desarrollo de las regiones y que afirman que con toda seguridad participarían del proceso decisorio. En contrapartida $80 \%$ de los entrevistados no había oído hablar de la futura elección de gobernadores regional. Cuando se aborda el nivel de información sobre el traspaso de competencia y atribución a los gobiernos regionales, el desconocimiento de los entrevistados llegaba a cerca del 90\%. Estos datos muestran la necesidad de información a la población sobre el proceso electoral y de las acciones de descentralización en curso en el país.

Es importante enfatizar que estos procesos de descentralización son complejos, por tratarse de una reforma del Estado. Al nivel de descentralización política, la principal medida corresponde a la elección del gobernador regional y al ajuste de la elección de los consejeros regionales. (Opazo, 2020; Valenzuela, 2015; Von Baer, 2016; Montecinos, 2020). Ese cambio, modificará completamente la dinámica política regional pues se trata "de uno de los componentes más complejos del proceso general de descentralización iniciado en Chile" (Von Baer, 2017 p. 69). Con respecto a la descentralización admisntrativa, Ley 21.074 de 2018 representa un ascenso, pues introduce una serie de modificaciones, con la intención de fortalecer la regionalización en Chile, entregando mayor autonomía en la gestión y aumento de funciones y atribuciones de los gobiernos regionales. A pesar de eso, aún no hay una ley de financiamiento y responsabilidad fiscal regional, a pesar de existir reciente propuestas aportadas desde la sociedad civil.

\section{Consideraciones finales}

En las consideraciones finales se puede señalar que se han aprobado un conjunto de leyes cuyo el objetivo es avanzar con el proceso de descentralización del Estado, como se nota a través de la aprobación de las últimas reformas constitucionales. A través de los datos producido por el IDERE en la última década, observase una propensión positiva en el crecimiento positivo de las regiones en sus indicadores, no obstante, se evalúa que la mayor concentración de desarrollo está en el centro y en algunas regiones del norte y la zona austral, mientras que la zona centro-sur es la que se presenta en peor posición 


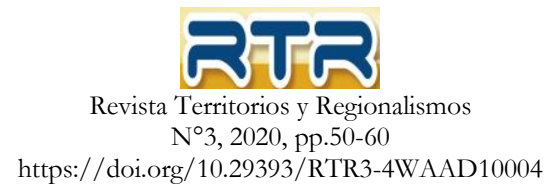

relativa, evidenciado que está condición es una tendencia histórica, que podrán ser minimizadas con el proceso descentralizador del Estado y mayor autonomía de las regiones para crearse estrategias de desarrollos efectiva, pensando en la singularidad y la potencialidad que poseen las regiones .

Cabe resaltar, que la principal medida apuntada para la descentralización por la Comisión Asesora Presidencial (2014), la elección democrática de los gobernadores regionales aún no ha sido realizada. Para cumplir el objetivo de la descentralización es necesario transferir a las regiones mayores grados de poder, para garantizar un avance en ese proceso que incluya la representación política y un consecuente plan de desarrollo para las regiones.

La decisión de cambio en la fecha para elección de los gobernadores como previsto originalmente, no fue bien recibido por los actores sociales y académicos del país, el consejo regional del Biobío (2020), por ejemplo, hizo una declaración pública, en junio de este año, a favor de la regionalización y descentralización, rechazando el aplazamiento de la elección de los gobernadores regionales, considerando su postergación un retroceso a todo este proceso. Montecinos y Varas (2020) a su vez, afirman que las razones para posponer las elecciones regionales no son razones técnicas ni sanitarias y justifican que estas fueron determinadas por razones políticas y electorales.

Sin embargo, además de la elección directa de los gobernadores regionales, que es urgente pero no suficiente para sostener un proyecto de desarrollo territorial, es necesario garantizar herramientas que endosen la autonomía de esos gobiernos para un efectivo desarrollo territorial, como las implementaciones de la Política Nacional de Ordenamiento Territorial (PNOT) y Planes Regionales de Ordenamiento Territorial (PROT), como ha sido planteado por Orellana y Arenas (2019), pues, resulta indispensable para avanzar en la descentralización y el empoderamiento regional, entendiendo que para un avance en la descentralización política, es primordial conceder a los gobiernos regionales autonomía, y garantizar ingresos que impulsen el desarrollo de las regiones. Así, la asignación de recursos a las regiones y la responsabilidad fiscal ha sido un gran desafío planteado por los autores y requieren un análisis específico.

Montecinos (2020) destaca que más allá de la autonomía de las regiones en el proceso de descentralización, como se ha planteado, es un ejercicio de relación y cooperación intergubernamental que debe contribuir para la implementación y consolidación de políticas públicas, puesto que de lo contrario podría provocar en la práctica un contrasentido la descentralización.

Así, no pretende ser conclusivo en este punto, puesto que el proceso de elección democrática para gobiernos regionales aún no ha sucedido. Igualmente, conforme a lo planteado por Opazo (2020), se vislumbra que posterior a 2024, chile entraría en una nueva fase de la descentralización, que nos permitiría un mejor análisis de los logros de la descentralización política para el progreso de las regiones. La expectativa es que, en un futuro próximo, Chile empezará a vivir un proceso inédito de descentralización y un avance en su democracia, dado que por primera vez en la historia republicana se elegirán autoridades de nivel regional (Montecinos, 2020). A partir de los datos mostrado por el Barómetro Regional (2019) se infiere una demanda por parte de los ciudadanos por mayores informaciones de los logros de las reformas descentralizadora en el país y las futuras elecciones de los gobernadores, comprendiendo que para una efectiva descentralización participativa y democracia territorial sea necesario instituir acciones de participación ciudadana que contribuyan a la construcción de un Chile descentralizado.

Como una última reflexión y posibilidad de estudio futuro, autores como Montecinos (2020), Valenzuela (2015) Opazo (2020), han demostrado una incertidumbre con las relaciones intergubernamentales que serán establecidas entre las diferentes autoridades regionales - Gobernado regional, que será electa por la ciudadanía a partir del año 2021 de la misma forma que la elección del intendente regional, que será designada por el gobierno central- considerando la dinámica de poder que 


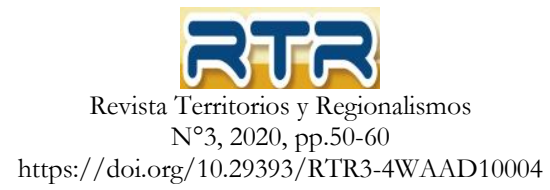

se establecerá, una vez que las autoridades supra citadas, van a tener atribuciones y competencias similares. En ese contexto, es necesario certificar que ese modelo dúo de autoridades regionales no sea una expresión de la tesis diseñada Ortiz \& Valenzuela (2018), donde a elite chilena acepta que la administración se descentraliza, mientras el poder político no, siendo necesario romper con la hegemonía que prevalece en el país. Para eso conviene asegurar que los chilenos y chilenas sean protagonistas de los cambios en marcha y que las regiones tengan la oportunidad de fomentar su propio desarrollo.

\section{Bibliografía}

Arenas, F. y Orellana, A. (2019) Aportes desde el ordenamiento territorial a la descentralización política y administrativa del país. En Von Baer, H. Bravo, N. (Eds.) Desarrollo Territorial Colaborativo. Descentralizando poder, competencias y recursos. Temuco: Ediciones Universidad de La Frontera Barómetro Regional (2019) Encuesta Barómetro Regional 2019 "Chile visto por sus regiones". Recuperado de https://ceruach.cl/wp-content/uploads/2020/03/Presentacion-Nacional-Barometro2 compressed.pdf

Cartes (2018) A. C. La regionalización en Chile dónde estamos y hacia dónde vamos. Montero, V. Muñoz, W. Simon, J.(eds.) En transformaciones en la política y desafíos para gobernar en el siglo XXI (pp 193226) Concepción: Editorial Universidad de Concepción.

Comisión Asesora Presidencial (2014) Informe Comisión Asesora Presidencial para la Descentralización y la Regionalización. Recuperado de https://prensa.presidencia.cl/lfi-content/otras/informescomisiones/InformeDescentralizacion.pdf

Consejo regional del Biobío (2020) Declaración Pública. Recuperado de

http://chiledescentralizado.cl/wp-

content/uploads/2020/06/DeclaracionPublicaCoreGobRegional.pdf

Cossani, C. V. Bonivento, J. H. (2014) ¿nuevas propuestas sobre descentralización regional? un análisis a la agenda legislativa. Recuperado de

https://ichem.uautonoma.cl/wp-content/uploads/2014/11/Nuevas-propuestas-sobre-

descentralizaci $\% \mathrm{C} 3 \% \mathrm{~B} 3 \mathrm{n}$-regional-Vial-Hern $\% \mathrm{C} 3 \% \mathrm{~A} 1 \mathrm{ndez}$.pdf

Dazarola, G. (2019) Descentralización en Chile Avances y temas pendientes. Recuperado de

https://obtienearchivo.bcn.cl/obtienearchivo?id=repositorio/10221/27720/1/BCN Estado Descentr alizacion Chile 2019 def.pdf

IDERE (2019) Índice de desarrollo regional. Recuperado de

https://cdn-ua.hostingreactor.com/ua_www/cache/wp-content/uploads/2018/10/UAutonoma-

2019-IDERE-Digital-completo-BAJA.pdf

Iriarte, P. (2016) Entre la Región y la Comuna: descentralización y municipios bajo la mirada de los Consejeros Regionales de Chile Volumen 4, no1. Recuperado de

https://revistaepe.utem.cl/articulos/entre-la-region-y-la-comuna-descentralizacion-y-municipios-bajola-mirada-de-los-consejeros-regionales-de-chile/

Marcel, M. C. (2016) Economía y territorio: ¿existe una relación entre desarrollo territorial, crecimiento e inclusión. Von Baer H. (Eds.) en El arranque de la descentralización desatando las amarras del centralismo chileno. Temuco: Ediciones Universidad de La Frontera

Montecinos, E. (2020). Elección de gobernadores regionales en Chile: escenarios de cambio en las relaciones intergubernamentales. Revista de ciencia política (Santiago)

https://dx.doi.org/10.4067/S0718-090X2020005000101

Montecinos, E. (2005) Antecedentes sobre la relación histórica centralismo y descentralización en Chile. Revista Venezolana de Gerencia (RVG) Año 10. n 31 


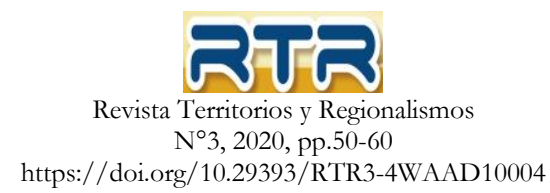

Montecinos, E. Varas, J. (2020) [Opinión] No al nuevo intento por posponer Elecciones Regionales Recuperado de https://www.poderyliderazgo.cl/opinion-no-al-nuevo-intento-por-posponer-eleccionesregionales/

OECD (2009) Organización para la Cooperación y el Desarrollo Económicos, Estudios Territoriales de la OCDE: Chile 2009, Ministry of the Interior, Chile, Santiago de Chile. Doi https://doi.org/10.1787/9789568468187-es

Opazo, O. (2020) las leyes de descentralización en chile: eje del cambio de la intergubernamentalidad pasando de la jerarquía a la negociación RIEM, N²1, año XI http://dx.doi.org/10.4067/S071917902020000100005

Ortiz, E. y Valenzuela, E. (2018). Chile, un siglo de pugna por la democratización de las regiones. Representación minimizada y centralismo transversal. Estudios Políticos (Universidad de Antioquia), 52, pp. 36-56. http://doi.org/10.17533/udea.espo.n52a03

Portales, D. (2016) El proceso de reformas pro descentralización en chile: actores y escenarios. Von Baer, H. (Eds.) en El arranque de la descentralización desatando las amarras del centralismo chileno. Temuco: Ediciones Universidad de La Frontera

Valenzuela, E. (2015) el modelo dual-incremental de regionalización en chile: intendentes electos y gobernadores delegados. Recuperado de https://revistariem.cl/index.php/riem/article/view/23, pp. 173-194

Von Baer, H (2017) Descentralización 2.0 Construyendo la gobernanza regional que Chile necesita: un desafío país. Temuco: Ediciones Universidad de La Frontera. Recuperado de http://chiledescentralizado.cl/wp-content/uploads/2017/10/LIBRO-Descentralizacion-2.0-v.final01.10.17.pdf

Von Baer, H (2016) El arranque de la descentralización desatando las amarras del centralismo chileno (ed.), Temuco, Universidad de La Frontera.

Von Baer, H Rozas, M. y Bravo, N. (2016) La elección de intendentes (gobernadores regionales): reforma madre de la descentralización en chile. Autor, en El arranque de la descentralización desatando las amarras del centralismo chileno. Temuco: Ediciones Universidad de La Frontera.

Von Baer, H. Portales (2019) Hacia un Desarrollo Territorial Colaborativo: hitos, aprendizajes y nuevos desafíos. En Von Baer, H. Bravo, N. (Eds) Desarrollo Territorial Colaborativo Descentralizando poder, competencias y recurso. Temuco: Ediciones Universidad de La Frontera. Recuperado de http://chiledescentralizado.cl/wp-content/uploads/2019/08/LIBRO-Desarrollo-territorial-

colaborativo-Portada-e-Indice.pdf 